九州大学学術情報リポジトリ

Kyushu University Institutional Repository

\title{
Doped organic light emitting diodes having a 650-nm-thick hole transport layer
}

\author{
Yamamori, Asuka \\ Department of Functional Polymer Science, Faculty of Textile Science and Technology, Shinshu \\ University
}

Adachi, Chihaya

Department of Functional Polymer Science, Faculty of Textile Science and Technology, Shinshu University

Koyama, Toshiki

Department of Functional Polymer Science, Faculty of Textile Science and Technology, Shinshu University

Taniguchi, Yoshio

Department of Functional Polymer Science, Faculty of Textile Science and Technology, Shinshu University

http://hdl. handle. net/2324/19443

出版情報: Applied Physics Letters. 72 (27), pp.2147-2149, 1998-04-27. American Institute of Physics

バージョン:

権利関係: Copyright 1998 American Institute of Physics. This article may be downloaded for personal use only. Any other use requires prior permission of the author and the American Institute of Physics. 


\title{
Doped organic light emitting diodes having a 650-nm-thick hole transport layer
}

\author{
Asuka Yamamori, Chihaya Adachi, ${ }^{a}$ Toshiki Koyama, and Yoshio Taniguchi \\ Department of Functional Polymer Science, Faculty of Textile Science and Technology, Shinshu University, \\ Ueda, Nagano 386, Japan
}

(Received 17 November 1997; accepted for publication 27 February 1998)

\begin{abstract}
We have succeeded in fabricating a thick-film organic light emitting diode having a doped hole transport layer (DHTL). The basic cell structure is anode DHTL/emitter layer/cathode. The DHTL is composed of a hole transporting polycarbonate polymer (PC-TPB-DEG) and tris(4-bromophenyl)aminium hexachloroantimonate (TBAHA) as a dopant. As an emitter, we used tris(8-hydroxyquinoline) aluminum (Alq). With a 650-nm-thick DHTL, the device showed considerable reduction in cell resistance compared with an anode/nondoped HTL/Alq/cathode device with the same HTL thickness. Although the electroluminescent quantum efficiency $\Phi_{L}$ was rather low in the doped device, we should be able to increase it by interposing a thin tetraphenylbendidine (TPB) layer between the DHTL and the emitter layer while keeping the driving voltage low. The anode/DHTL $(650 \mathrm{~nm}) / \mathrm{TPB}(50 \mathrm{~nm}) / \mathrm{Alq}(50 \mathrm{~nm}) /$ cathode showed luminance of more than $4004 \mathrm{~cd} / \mathrm{m}^{2}$ at $10.0 \mathrm{~V}$ and $220 \mathrm{~mA} / \mathrm{cm}^{2}$. (C) 1998 American Institute of Physics. [S0003-6951(98)03317-8]
\end{abstract}

In recent typical organic light emitting diodes (OLEDs), the total thickness of organic layers was restricted to less than $150 \mathrm{~nm} .{ }^{1}$ Although such an ultrathin film enabled us to inject and transport sufficient charge carriers with low driving voltage (less than $10 \mathrm{~V}$ ), pinholes based on the ultrathin films and resulting instability of the device performance are serious problems for practical device application. Several attempts on this problem have shown that the use of conducting polymers and low molecular materials as buffer layers between an anode and a hole transport layer (HTL) could suppress leakage currents effectively. Yang et al. ${ }^{2}$ and Antoniadis et al. ${ }^{3,4}$ successfully used doped polyaniline (PANI) and Shirota et al. ${ }^{5}$ used starburst polyamines as the buffer layer. Excellent coverage of pinholes with these buffer materials is thought to suppress noisy leakage currents. More recently, Antoniadis reported on doped tetraphenylbendidine (TPB) as the effective buffer layer. ${ }^{6}$

Our approach to this problem is the construction of thicker organic layers than those used at present. However, the use of 500-nm-thick organic layers, for example, normally requires a very high driving voltage (over $100 \mathrm{~V}$ ), which easily leads to breakdown by electric discharge. One of the previous successful attempts to make thick devices is the light emitting electrochemical cell (LEC) proposed by Pei et al. ${ }^{7-15}$ They demonstrated $15-\mu \mathrm{m}$-thick devices by mixing electroconducting and ion-conducting polymers. ${ }^{7,8}$ In this device, the phase separation of the two polymers is a significant problem and various efforts to form a bicontinuous network morphology were attempted. ${ }^{12}$

In this letter, we report a doped organic light emitting diode (DOLED) having a thick doped hole transport layer (DHTL). The DHTL was chemically doped with an acceptor molecule, although electrochemical doping was performed in situ by applying a driving voltage in the LEC. We used the

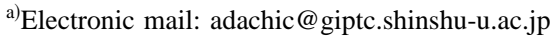

hole transporting polycarbonate polymer (PC-TPB-DEG) as a HTL and tris(4-bromophenyl)aminium hexachloroantimonate, TBAHA, ${ }^{16,17}$ as a dopant (Fig. 1), because it is well established that TBAHA plays a useful role as a one-electron oxidizing agent for polyvinylcarbazoles (PVCz). ${ }^{18,19}$ The previous reports stimulated us to use this dopant molecule. The combination of PC-TPB-DEG and TBAHA allowed us to construct thick devices and ensured there was no phase separation like the LEC.

Figures 1 and 2 show chemical structures and the two DOLED device structures used in this study, respectively. PC-TPB-DEG was prepared according to Ref. 20. TBAHA was purchased from Aldrich Co. Ltd. and was used without further purification. After plasma washing (Samco Int. Inc., Model BP-1) on an ITO-film-coated glass substrate, a thick DHTL was prepared on the ITO by spin coating from a solution containing $50 \mathrm{mg}$ of PC-TPB-DEG and TBAHA $(0.1,1,10,20 \mathrm{wt} \%$ against PC-TPB-DEG content) in $1 \mathrm{ml}$ of dichloromethane. The spinning rate was $1000 \mathrm{rpm}$. The thicknesses of the spin-coating films were typically $650 \mathrm{~nm}$.

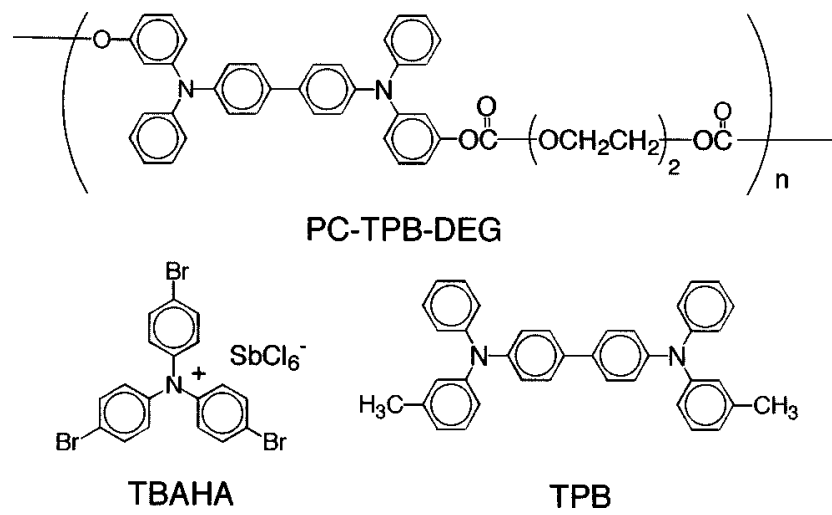

FIG. 1. Molecular structures used in this study, PC-TPB-DEG, TBAHA and TPB. 


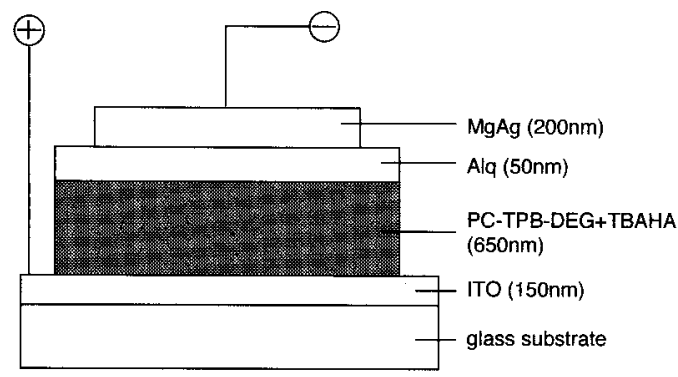

(a)

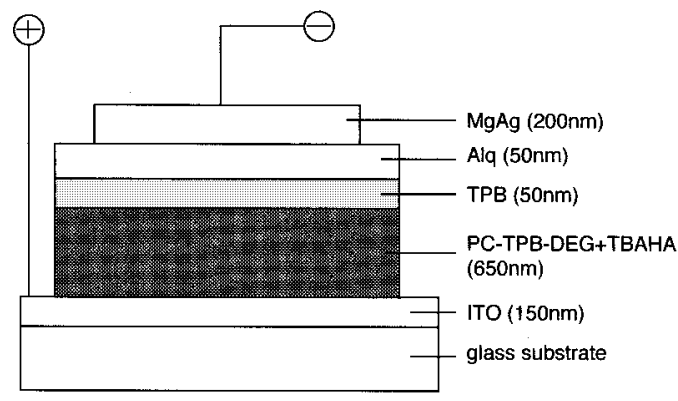

(b)

FIG. 2. Two structures of doped organic light emitting diode (DOLED). (a) Basic cell structure; (b) improved cell structure. A thin TPB layer was inserted between PC-TPB-DEG and Alq.

The films were then heated at $80{ }^{\circ} \mathrm{C}$ for $1 \mathrm{~h}$ in air to evaporate residual solvent. Tris (8-hydroxyquinoline) aluminum $(50 \mathrm{~nm})$ as an emitter material, and a $\mathrm{Mg}-\mathrm{Ag}$ cathode (200 $\mathrm{nm})$ were vacuum deposited onto the polymer film at pressures around $6 \times 10^{-6}$ Torr. The active area of the devices was $2 \times 2 \mathrm{~mm}^{2}$. For comparison, we also fabricated a device of the same thickness without TBAHA. Furthermore, we fabricated an improved device, in which a thin TPB layer was interposed between the DHTL and Alq layers.

Figure 3(a) shows the current density-voltage $(J-V)$ characteristics of ITO/PC-TPB-DEG:TBAHA $(650 \mathrm{~nm}) /$ Alq(50 nm)/MgAg devices with various TBAHA doping concentrations $(0,0.1,1,10$, and $20 \mathrm{wt} \%)$. In the case of nondoped device, it was really difficult to observe a large injection current, even though a high driving voltage of over $30 \mathrm{~V}$ was applied. On the other hand, the doped devices showed a pronounced injection current depending on the TBAHA concentrations. At the doping level of $20 \mathrm{wt} \%$, in particular, we could achieve a high current density exceeding $244 \mathrm{~mA} / \mathrm{cm}^{2}$ under an applied voltage of only $7.0 \mathrm{~V}$. This $J-V$ relation was the same as that for a device composed of the typical thin organic layers: anode/TPB $(60 \mathrm{~nm}) / \operatorname{Alq}(70$ $\mathrm{nm}) /$ cathode. Figure 3(b) shows luminance-current density $(L-J)$ characteristics of the four devices. The devices doped with 0.1 and $1 \mathrm{wt} \%$ of TBAHA showed similar electroluminescent (EL) efficiencies $\Phi_{L}$, and these values were comparable with $\Phi_{L}$, of the typical thin film device, $1 \%-2 \% .^{21,22}$ The devices with the TBAHA concentration of 10 and 20 wt $\%$, however, showed rather low efficiency. Thus, the compatibility of low driving voltage and high $\Phi_{L}$, should be developed.

Next, we tried to interpose a thin TPB layer $(50 \mathrm{~nm})$ between the DHTL and Alq layer [Fig. 2(b)], because we thought that serious exciton energy transfer from Alq to DHTL could be responsible for quenching the Alq fluorescence. Also, we supposed that electron injection into DHTL
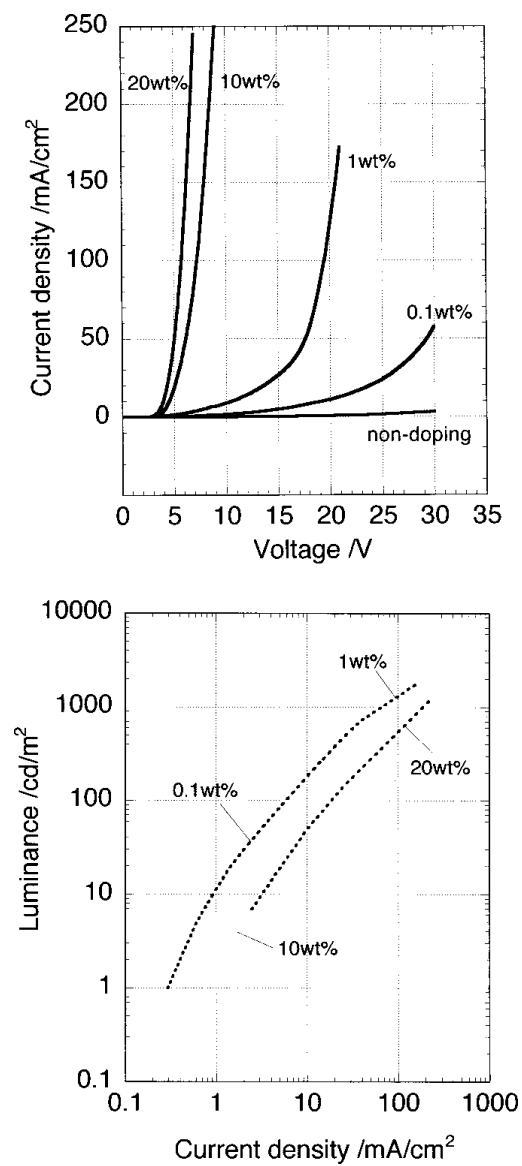

FIG. 3. (a) Current-density-voltage characteristics $(J-V)$ of ITO/PC-TPBDEG: TBAHA/Alq/MgAg devices with various dopant concentrations: 0 , $0.1,1,10$, and $20 \mathrm{wt} \%$. (b) Luminance-current density characteristics $(L-J)$ of ITO/PC-TPB-DEG: TBAHA/Alq/MgAg devices with various dopant concentrations: $0,0.1,1,10$, and $20 \mathrm{wt} \%$.

from the Alq layer caused imbalance of hole/electron injection and transportation, which resulted in low EL efficiency. Each PC-TPB-DEG:TBAHA (1, 10, and $20 \mathrm{wt} \%)$ layer had absorption based on a charge transfer complex at around 485 $\mathrm{nm}$. This species can receive an energy transfer from Alq excitons, which leads to exciton quenching. Figure 4(a) clearly shows the effect of inserting a thin TPB layer. DHTL (10 wt \%)/Alq (a) and DHTL/TPB/Alq (b) devices were compared. The $L-J$ characteristics show that $\Phi_{L}$, increased by a factor of 3.4 with the TPB insertion and the brightness reached $4004 \mathrm{~cd} / \mathrm{m}^{2}$ at $10.0 \mathrm{~V}$ and $220 \mathrm{~mA} / \mathrm{cm}^{2}$. Thus, it is possible that the inserted TPB layer caused the radiative decay of excitons inside the Alq and blocked electrons effectively. With our present experimental results, however, it is hard to clarify which processes operate as a dominant factor for getting high EL efficiency and we need more detailed experimental consideration. With the TPB insertion, the increase in driving voltage was not seriously high, as shown in Fig. 4(b), which is desirable. At $J=100 \mathrm{~mA} / \mathrm{cm}^{2}$, the increase of driving voltage in this device (b) was only $1.0 \mathrm{~V}$ in comparison with that in the device (a). Thus, we succeeded in combining both a low driving voltage and high luminance with the three layer structure.

Here, we consider the role of the TBAHA dopant. In the first place, the increase in carrier concentration under thermal equilibrium in the DHTL is possible reason for the reduction
cense or copyright; see http://apl.aip.org/about/rights_and_permission 

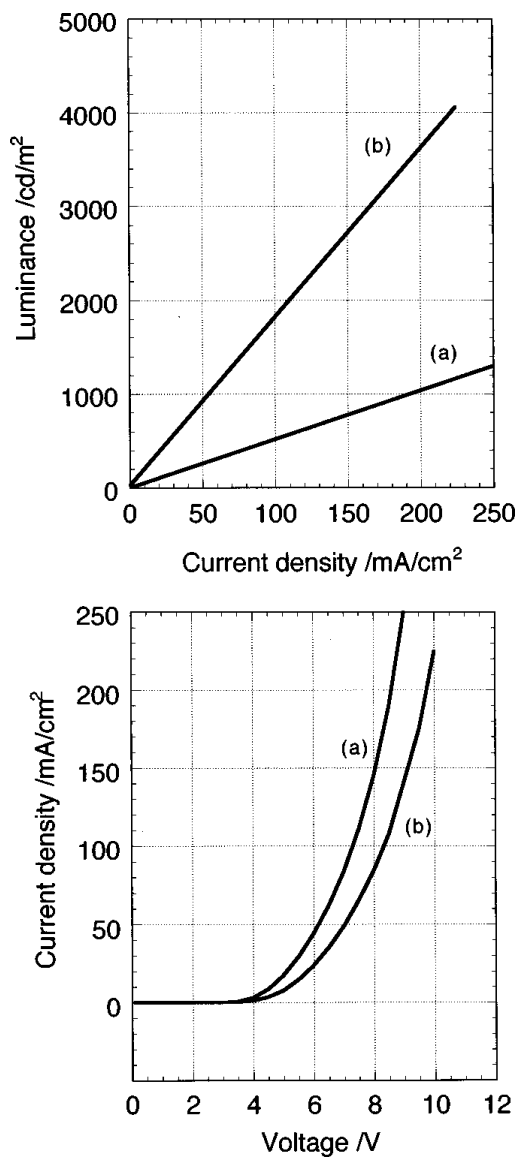

FIG. 4. (a) Current-density-voltage characteristics $(J-V)$. (a) ITO/PCTPB-DEG: TBAHA $(10 \mathrm{wt} \%) / \mathrm{Alq} / \mathrm{MgAg}$, (b) ITO/PC-TPB-DEG: TBAHA $(10 \mathrm{wt} \%) / \mathrm{TPB} / \mathrm{Alq} / \mathrm{MgAg}$. (b) Luminance-current density characteristics $(L-J)$. (a) ITO/PC-TPB-DEG: TBAHA $(10 \mathrm{wt} \%) / \mathrm{Alq} / \mathrm{MgAg}$. (b) ITO/PCTPB-DEG:TBAHA $(10 \mathrm{wt} \%) / \mathrm{TPB} / \mathrm{Alq} / \mathrm{MgAg}$.

in cell resistivity. ${ }^{16,18}$ Thus, improved carrier transport properties are anticipated to contribute to the reduced operating voltage. Second, we can also expect a reduction in hole injection barrier height at the anode/DHTL interface. To understand the role of the TBAHA dopant, we measured the ionization potential $\left(I_{p}\right)^{23}$ of DHTLs. The $I_{p}$ values of 10 wt $\%$ and even $20 \mathrm{wt} \%$ was $5.48 \mathrm{eV}$, the same as that of nondoped HTL. It seems likely, however, that the carrier injection from anode to DHTL occurs through the localized levels created by the TBAHA dopant. To understand the detailed operating mechanism of the DOLED, we need fine measurements of $I_{p}$ values, carrier concentrations, and carrier mobilities.

For further development, we are now studying the use of other host and dopant materials for the DHTL and the formation of thick electron transport layers (ETL) with adequate dopants. In addition, the formation of thick organic layers is also expected for making organic laser diodes (OLDs). ${ }^{24}$ The most promising recent structure for a practical OLD is a waveguide type ${ }^{25-29}$ In this structure, indiumtin-oxide (ITO) hole injection anode and a magnesium- or aluminum-based metal electron injection cathode suppress the waveguiding of photons, resulting in a high laser threshold. The formation of thick carrier transport layers between an electrode and a waveguiding emitter layer is expected to reduce the laser threshold and is unavoidable. ${ }^{29}$ In particular, it is necessary to separate the metal cathode and the emitter Downloaded 06 Apr 2011 to 133.5.128.1. Redistribution subject to AlP layer by inserting a thick ETL. We believed that the feasibility of thick layers will open up novel possibilities of organic LEDs.

In conclusion, we fabricated DOLED having DHTL. With the 650-nm-thick DHTL, we could combine both a low driving voltage and high $\Phi_{L}$. Excellent performance of the thick OLED was attributed to the thick DHTL layer as a hole injection and transport layer and also the insertion of a thin TPB layer as an exciton blocking layer and electron blocking layer.

The authors thank M. Ohta (Ricoh Co. Ltd.,) for the preparation of PC-TPB-DEG and K. Nagai for the $I_{p}$ measurement.

${ }^{1}$ See, for example, Inorganic and Organic Electroluminescence/EL96 Berlin, edited by R. H. Mauch and H.-E. Gumlich (Wissenschaft und Technik, Berlin, 1996).

${ }^{2}$ Y. Yang and A. J. Heeger, Appl. Phys. Lett. 64, 1245 (1994).

${ }^{3}$ H. Antoniadis, M. R. Hueschen, J. McElvain, J. N. Miller, R. L. Moon, D. B. Roitman, and J. R. Sheets, Am. Chem. Soc. Polym. Prepr. 38, 382 (1997).

${ }^{4}$ J. R. Sheets, H. Antoniadis, M. R. Hueschen, W. Leonard, J. Miller, R. Moon, D. Roitman, and A. Stocking, Science 273, 884 (1996).

${ }^{5}$ Y. Shirota, Y. Kuwabara, and H. Inada, Appl. Phys. Lett. 65, 807 (1994).

${ }^{6} \mathrm{See}$, for example, Proceedings of Conference for Electronic Materials in Santa Barbara, CA, 1996, and Photoinduced Charge Transfer Center Symposium: Materials for Electronics and Imaging in Rochester, NY, 1997.

${ }^{7}$ Q. Pei, G. Yu, C. Zhang, Y. Yang, and A. J. Heeger, Science 269, 1086 (1995).

${ }^{8}$ Q. Pei, Y. Yang, G. Yu, C. Zhang, and A. J. Heeger, J. Am. Chem. Soc. 118, 3922 (1996).

${ }^{9}$ Y. Yang and Q. Pei, Appl. Phys. Lett. 68, 2708 (1996).

${ }^{10}$ Q. Pei and Y. Yang, J. Am. Chem. Soc. 118, 7416 (1996).

${ }^{11}$ V. Cimrova, W. Schmidt, R. Rulkens, M. Schulze, W. Meyer, and D. Neher, Adv. Mater. 8, 585 (1996).

${ }^{12}$ Y. Cao, G. Yu, A. J. Heeger, and C. Y. Yang, Appl. Phys. Lett. 68, 3218 (1996).

${ }^{13}$ J. Gao, G. Yu, and A. J. Heeger, Appl. Phys. Lett. 71, 1293 (1997).

${ }^{14}$ Y. Yang and Q. Pei, J. Appl. Phys. 81, 3294 (1997).

${ }^{15}$ Y. Yang and Q. Pei, Appl. Phys. Lett. 70, 1926 (1997).

${ }^{16}$ Y. Yamamoto, S. Kanda, S. Kusabayashi, T. Nogaito, K. Ito, and H. Mikawa, Bull. Chem. Soc. Jpn. 38, 2015 (1965).

${ }^{17}$ F. A. Bell, A. Ledwith, and D. C. Scherrington, J. Chem. Soc. C , 2719 (1969).

${ }^{18}$ H. Block, M. A. Cowd, and S. M. Walker, Polymer 18, 781 (1977).

${ }^{19}$ R. H. Partridge, Polymer 24, 733 (1983).

${ }^{20}$ W. Mychajlowskij, G. Liebermann, W. W. Limburg, J. F. Yanus, and D. K. Murti, U.S. Patent No. 5,419,992 (May 30, 1995).

${ }^{21}$ C. W. Tang and S. A. VanSlyke, Appl. Phys. Lett. 51, 913 (1987).

${ }^{22}$ S. A. VanSlyke, C. H. Chen, and C. W. Tang, Appl. Phys. Lett. 69, 2160 (1996).

${ }^{23}$ Ionization potentials were determined using a Riken-Keiki AC-1.

${ }^{24}$ C. Adachi, T. Tsutsui, and S. Saito, Appl. Phys. Lett. 57, 531 (1990).

${ }^{25}$ F. Hide, M. A. Diaz-Garcia, B. J. Schwartz, M. R. Andersson, P. Pei, and A. J. Heeger, Science 273, 1833 (1996).

${ }^{26}$ M. A. Diaz-Garcia, F. Hide, B. J. Schwartz, M. D. McGehee, M. R. Andersson, and A. J. Heeger, Appl. Phys. Lett. 70, 3191 (1997).

${ }^{27}$ N. D. Kumar, J. D. Bhawalkar, P. N. Prasad, F. E. Karaz, and B. Hu, Appl. Phys. Lett. 71, 999 (1997).

${ }^{28}$ V. G. Kozlov, V. Bulovic, P. E. Burrows, and S. R. Forrest, Nature (London) 389, 362 (1997).

${ }^{29}$ F. Hide, B. J. Schwartz, M. A. Diaz-Garcia, and A. J. Heeger, Chem.

Phys. Lett. 256, 424 (1996). 